\title{
INVESTIGATING THE LATERAL STABILITY OF THREE-WHEELED SCOOTER TAXI DUE TO TYRE-ROAD FORCES
}

\author{
G. A. Asuelinmen ${ }^{1, *}$, S. J. Ojolo ${ }^{2}$ and O. O. Ajayi ${ }^{3}$ \\ $\mathbf{1}, \mathbf{2}, \mathbf{3}$, DePARTMENT OF MeChANICAL ENGINEERING, UniverSity OF LAGOS, AKOKA, LAGOS STATE, NIGERIA \\ E-mail addresses; ${ }^{1}$ asuegeo@gmail.com, 2 ojolosunday@yahoo.com, 3 bosun_ajayi@yahoo.com
}

\begin{abstract}
Three-wheeled scooter taxi (TWST) that is currently prevalent in developing countries, is fuel efficient and cheap. It is used mainly for commercial purposes, also as a means of reducing unemployment and tackling poverty. However, the vehicle is unstable and prone to accidents due to its design configuration. The aim of this research work is to investigate the lateral stability of TWST due to Tyre-Road Forces. Therefore, lateral stability equations for three-wheeled vehicle (TWV) were developed and used in the analysis of TWST based on parametric values obtained from static test. The results showed that the vehicle is stable with respect to lateral stability, which is in line with what was obtained from literature, thereby validating the models with the driver alone. However, with two or more occupants the vehicle became unstable. Possible ways of eliminating this instability were discussed. The static test procedure, if adopted and legislated upon, would significantly enhance safety of life and properties of stakeholders in developing countries.
\end{abstract}

Keywords: Three-wheeled scooter Taxi, Stability Analysis, Safety of life and properties, Legislation.

\section{INTRODUCTION}

Three-wheeled vehicle (TWV) is often referred to as tricycle, trike or three-wheeler. Their use varies according to need and purpose. They are used for recreational, agricultural and commercial purposes.

The commercial tricycle called the three-wheeled scooter taxi (TWST) is safer when compared with motorcycle and cheaper when compared with fourwheeled vehicle. The vehicle is fuel efficient and environmentally friendly [1 - 5]. These advantages have accentuated its use. With improvement in its comfortability it would be further enhanced.

However, the lateral stability of this vehicle is of concern. Few researchers $[1,6,7]$ have investigated this stability problem without much focus on the various loading conditions of the vehicle which could induce lateral instability. This instability places limitation on the speed and usage of the vehicle.

Therefore, the aim of this paper is to develop lateral stability models for delta trike design to enhance its speed, safety of life and properties and general acceptability of the vehicle in the market, both for private and commercial purposes by taking into consideration the specified loading conditions.

\section{MATERIALS AND METHODS}

\subsection{Theoretical Framework for Lateral Stability} of Delta Trike

Figure 1 shows a bicycle-model of a delta trike with body-centred coordinate adapted from literature [6, 8].

The vehicle model is assumed to be under steady state condition with the velocity fairly constant. This is the commonest type of motion in real life. It is therefore appropriate for the determination of lateral stability of vehicles. The vertical motion of the model, the angular motion in roll and pitch axes are neglected. The analysis is restricted to planar motion involving lateral acceleration, yaw rate and lateral forces due to tyre deformation.

Nomenclature: $\mathrm{U}$ is the velocity in $\mathrm{x}$ direction, $\mathrm{V}$ is the velocity in $y$ direction, $\Omega z$ is the angular velocity in $z$ direction, $I_{z}$ is the moment of inertial about centre of gravity (C. G.) in $z$ direction, FYF is front lateral force in $y$ direction, $2 F_{Y R}$ is rear lateral force in y direction, $m$ is the mass, $W_{B}$ is wheelbase, $L_{1}$ is the distance from $C$. $G$. to centre of front tyre and $L_{2}$ is the distance from C. G. to centre of rear tyre.

* Corresponding author, tel: +234 8037255380 


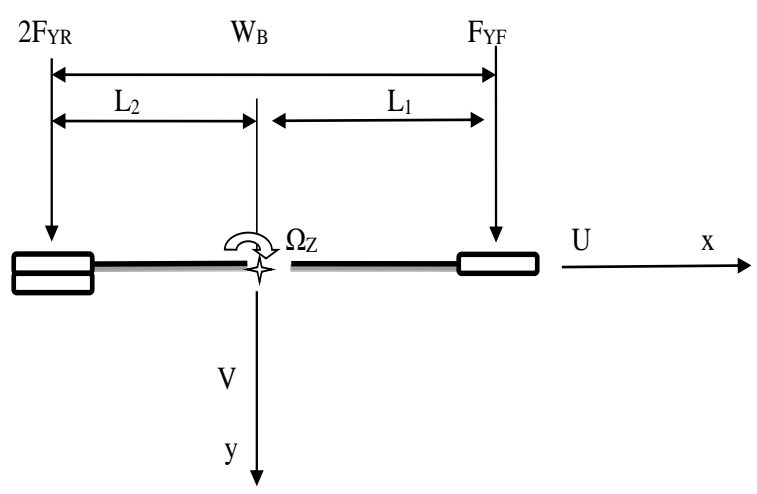

Fig. 1: Bicycle Model 1 of Plane Motion of Delta Tricycle

Equation derivation was based on that of four vehicles [8], with air drag taken into consideration.

Applying Newton's and Euler's equations, the equations of motion of the vehicle in the $y$ direction, due to changes in momentum in $y$ and $x$ directions and net moment about centre of gravity based on that of four wheeled vehicle [8] are:

$m\left(\dot{V}+\Omega_{Z} * U\right)=2 F_{Y R}+F_{Y F}$

$I_{Z} \dot{\Omega}_{Z}=L_{1} F_{Y F}-2 L_{2} F_{Y R}$

The slip angle $(\alpha)$, is the angle between wheel direction and the tyre contact part. Slip angle increases more than the increase in lateral force with more loads.

Linear relationship exists between lateral force and slip angle up to about $5^{0}[8]$.

Therefore:

$$
\begin{aligned}
& F_{Y}=-C_{\alpha} \alpha \\
& F_{Y F}=-C_{\alpha F} \alpha_{F} \\
& 2 F_{Y R}=-2 C_{\alpha R} \alpha_{R}
\end{aligned}
$$

Fy and $\alpha$ are in opposite direction. To ensure that the simulation of the equation is in the first quadrant of Cartesian coordinate Society of Automotive Engineers (SAE) introduced negative sign into equation (3) so that cornering coefficient $\left(C_{\alpha}\right)$ can be positive [9] and also to avoid its negative impact on the final equation. Therefore,

$C_{\alpha}=\frac{\partial F_{y}}{\partial \alpha_{\alpha=0}}$

Slip angle can also be expressed as the ratio of the lateral velocities $\left(V_{L}\right)$ to the rolling velocities $\left(U_{H}\right)$. That is:

$\alpha=V_{L} / U_{H}$

Therefore, the front wheel and rear wheels lateral velocities are expressed in equations (8) and (9) respectively.

$$
\begin{aligned}
& V_{L F}=V+\Omega_{Z} L_{1} \\
& V_{L R}=V-\Omega_{Z} L_{2}
\end{aligned}
$$

The rolling velocity is approximately equal to the velocity of the vehicle, therefore:

$$
U_{H} \approx U
$$

Combining equations (8-10) based on equation (7) the front and rear slip angles become:

$$
\begin{aligned}
& \alpha_{F}=\frac{V+\Omega_{Z} L_{1}}{U} \\
& \alpha_{R}=\frac{V-\Omega_{Z} L_{2}}{U}
\end{aligned}
$$

Combining equations (1) to (12), the equations of motion then become:

$$
\begin{aligned}
& m\left(\dot{V}+\Omega_{Z} U\right)=-\left(\frac{C_{\alpha F}+2 C_{\alpha R}}{U}\right) V-\left(\frac{L_{1} C_{\alpha F}-2 L_{2} C_{\alpha R}}{U}\right) \Omega_{Z} \\
& \text { Iz } \dot{\Omega}_{\mathrm{Z}}=-\left(\frac{L_{1} C_{\alpha F}-2 L_{2} C_{\alpha R}}{U}\right) V-\left(\frac{L_{1}^{2} C_{\alpha F}+2 L_{2}^{2} C_{\alpha R}}{U}\right) Q_{Z}
\end{aligned}
$$

If $U$ remains constant, the dynamic equation can be written in vector-matrix form:

$$
\left[\begin{array}{cc}
m & \\
& I_{Z}
\end{array}\right]\left[\begin{array}{c}
\dot{V} \\
\dot{\Omega}_{Z}
\end{array}\right]+\left[\begin{array}{cc}
\left(C_{\alpha F}+2 C_{\alpha R}\right) / U & \left(\mathrm{~L} 1 C_{\alpha F}-2 L_{2} C_{\alpha R}\right) / U+m U \\
\left(L_{1} C_{\alpha F}-2 L_{2} C_{\alpha R}\right) / U & \left(L_{1}^{2} C_{\alpha F}+2 L_{2}^{2} C_{\alpha R}\right) / U
\end{array}\right]\left[\begin{array}{c}
V \\
\Omega_{Z}
\end{array}\right]=\left[\begin{array}{l}
0 \\
0
\end{array}\right]
$$

The determinant can be written in the form below.

$$
\text { Det }\left[\begin{array}{cc}
m s+\left(C_{\alpha F}+2 C_{\alpha R}\right) / U & \left(L_{1} C_{\alpha F}-2 L_{2} C_{\alpha R}\right) / U+m U \\
\left(L_{1} C_{\alpha F}-2 L_{2} C_{\alpha R}\right) / U & I_{z} s+\left(L_{1}^{2} C_{\alpha F}+2 L_{2}^{2} C_{\alpha R}\right) / U
\end{array}\right]=0
$$

With the determinant expanded, the expression is the characteristic equation: 


$$
\begin{gathered}
m I_{z} s^{2}+m s\left(L_{1}^{2} C_{\alpha F}+2 L_{2}^{2} C_{\alpha R}\right) / U+I_{Z} s\left(C_{\alpha F}+2 C_{\alpha R}\right) / U+\left[\left(C_{\alpha F}+2 C_{\alpha R}\right) / U\right]\left[\left(L_{1}^{2} C_{\alpha F}+2 L_{2}^{2} C_{\alpha R}\right) / U\right]-\frac{\left(L_{1} C_{\alpha F}-2 L_{2} C_{\alpha R}\right)^{2}}{U^{2}}- \\
m\left(L_{1} C_{\alpha F}-2 L_{2} C_{\alpha R}\right)=0
\end{gathered}
$$

Rearrangement of the equation (17) results in equations (18) - (21):

$$
\begin{gathered}
m I_{Z} s^{2}+\left[m\left(L_{1}^{2} C_{\alpha F}+2 L_{2}^{2} C_{\alpha R}\right) / U+I_{Z}\left(C_{\alpha F}+2 C_{\alpha R}\right) / U\right] s+ \\
\frac{+L_{1}^{2} C^{2}{ }_{\alpha F}+4 L_{2 R}^{2}+2 C_{\alpha R} L_{2}^{2} C_{\alpha F}+2 C_{\alpha R} L_{1}^{2} C_{\alpha F}-L_{1}^{2} C^{2}{ }_{\alpha F}-4 L_{2}^{2} C^{2}{ }_{\alpha R}+4 L_{2} C_{\alpha R} L_{1} C_{\alpha F}}{U^{2}}-m\left(L_{1} C_{\alpha F}-2 L_{2} C_{\alpha R}\right)=0 \\
m I_{Z} s^{2}+\left[m\left(L_{1}^{2} C_{\alpha F}+2 L_{2}^{2} C_{\alpha R}\right) / U+I_{Z}\left(C_{\alpha F}+2 C_{\alpha R}\right) / U\right] s+ \\
\frac{+2 C_{\alpha R} L_{2}^{2} C_{\alpha F}+2 C_{\alpha R} L_{1}^{2} C_{\alpha F}+4 L_{2} C_{\alpha R} L_{1} C_{\alpha F}}{U^{2}}-m\left(L_{1} C_{\alpha F}-2 L_{2} C_{\alpha R}\right)=0 \\
m I_{Z} s^{2}+\left[m\left(L_{1}^{2} C_{\alpha F}+2 L_{2}^{2} C_{\alpha R}\right) / U+I_{Z}\left(C_{\alpha F}+2 C_{\alpha R}\right) / U\right] s+\frac{2 C_{\alpha R} C_{\alpha F}\left(L_{2}^{2}+L_{1}^{2}+2 L_{2} L_{1}\right)}{U^{2}}-m\left(L_{1} C_{\alpha F}-2 L_{2} C_{\alpha R}\right)=0 \\
m I_{z} s^{2}+\left[m\left(L_{1}^{2} C_{\alpha F}+2 L_{2}^{2} C_{\alpha R}\right) / U+I_{Z}\left(C_{\alpha F}+2 C_{\alpha R}\right) / U\right] s+\frac{2 C_{\alpha R} C_{\alpha F}\left(L_{2}+L_{1}\right)^{2}}{U^{2}}-m\left(L_{1} C_{\alpha F}-2 L_{2} C_{\alpha R}\right)=0
\end{gathered}
$$

Equation (21) is a second order characteristic equation. For the system to be stable, the last coefficient of the equation must be positive [8]. Therefore:

$$
\frac{2 C_{\alpha R} C_{\alpha F}(\mathrm{~L} 2+\mathrm{L} 1)^{2}}{U^{2}}+m\left(2 L_{2} C_{\alpha R}-L_{1} C_{\alpha F}\right)>0
$$

At high speed, the first term on the left hand side of equation (22) diminishes such that it can be written as:

$2 L_{2} C_{\alpha R}-L_{1} C_{\alpha F}>0$

The vehicle will understeer: it means that it will be laterally stable.

If however,

$2 L_{2} C_{\alpha R}-L_{1} C_{\alpha F}<0$

The vehicle will become unstable at a particular speed based on equation (21) being equated to zero. This condition is called oversteer.

With the aerodynamic reactions due to drag force $[10,11]$ the value of $L_{1}$ will change to $L_{1 A}$ and $L_{2}$ will change to $L_{2 A}$, when the frontal height centre of the aero pressure is greater than C.G. The values of cornering coefficients will also change. Otherwise equation (23) stands. The equation (23) with air-drag becomes (under steady state velocity):

$2 \mathrm{~L}_{2 \mathrm{~A}} \mathrm{C}_{\alpha \mathrm{RA}}-\mathrm{L}_{1 \mathrm{~A}} \mathrm{C}_{\alpha \mathrm{FA}}>0$

In motor vehicle dynamics, increase in normal load, will increase the slip angle in an increasing manner while lateral force will increase in a decreasing manner because of viscoelastic nature of tyre material. Therefore, cornering coefficient (which is now being called cornering stiffness in recent literature, $C_{\alpha}$ ) deceases with increases in lateral force. In addition, increase in normal load will increase lateral force and decrease cornering coefficient more proportionately (Goran et al., 2013). Consequently, from equation (23) if the Centre of Gravity (C.G.) of normal load is at distance $2 / 3$ from front wheel, the cornering coefficient will be the same in all the three tyres since the load will be same in each tyre. The equation becomes:

$2 L_{2}-L_{1}=0$

The vehicle will just be laterally stable.

For the same tyre, if the Centre of Gravity (C.G.) of normal load is at distance less $2 / 3$ of wheelbase from the front wheel, the front cornering coefficient of the front wheel will be less than each of the rear and also $2 L_{2}$ will greater than $L_{1}$. Therefore, the vehicle will be lateral stable at all speed [6]. Hence, equations (27), (28) and (29) hold:

$$
\begin{aligned}
& 2 L_{2} C_{\alpha R} \geq L_{1} C_{\alpha F} \\
& C_{\alpha R} \geq C_{\alpha F} \\
& 2 L_{2} \geq L_{1}
\end{aligned}
$$

Since $L_{2}+L_{1}=W_{B}$ the equation (29) becomes:

$$
\frac{2}{3} \geq \frac{L_{1}}{W_{B}}
$$

Consequently, equation (30) becomes:

$$
\frac{2}{3} \geq \frac{2 F_{Y R}}{m g}
$$

Where, $m g$ is the weight of the vehicle and $2 F_{Y R}$ is the weight of the rear wheels.

Equations (30) and (31) are referred to as Lateral Stability Factor (LSF) for Delta Trike with two rear 
wheels. Therefore, it can be safely concluded that for same tyre, the issue cornering coefficient in the determination of lateral stability is not relevant, all other things being equal. Lateral stability of a vehicle can be enhanced, for example, by introducing tyres with higher cornering coefficient or wider width at the rear.

\subsection{Test Procedure for Lateral Stability Determination of TWV with Two Rear Wheels}

There are various test procedures for lateral stability. The following are some of the methods for vehicle testing: Weight test method [6] and ISO (International Organization for Standardization) 4138 method (constant-speed test method, constantradius test method and constant steering-wheel angle test method) [14]. For the purpose of implementation of these tests in a developing country, weight test method is recommended because it is simple and less involving, though it may not be the best method. For lateral stability of a delta trike with the same tyre, the average weight of the rear wheels must be less than the average weight on the front wheel. That is, the rear wheels weight divide by the total weight of the vehicle must be less than $2 / 3$, which is the maximum lateral stability factor based on equations (30) and (31).

UNILAG Fluid Mechanics Laboratory was used for the static test. Items used for the test were: Weighbridge (1,000kg Avery Scale with wooden platform), Digital electronic scales $(180 \mathrm{~kg})$, Camera, Engineering Tape and Three TWST (Registration Numbers: BDG 252 QH, AGL7180, and AGL 532 QH).

The vehicles were mounted on the weighbridge in turn as shown Figure 2. The readings were taken for each of the vehicle and repeated to minimise reading errors. Also taken were the weights of individual wheels and necessary vehicle dimensions. The average overall weights of the vehicles were compared with the average of the sum of individual wheels loads. The difference in weights was within $1 \mathrm{~kg}$ or $0.28 \%$ of the average overall weights of vehicles, which is not significant.

Dimensions taken from the vehicles were: Wheelbase, wheel-track, horizontal distance from the ground centre of front axle to driver back support, horizontal distance from the ground centre of front axle to the passenger back support, vertical distance from the ground to the top of driver seat and vertical distance from the ground to the top of passenger seat.

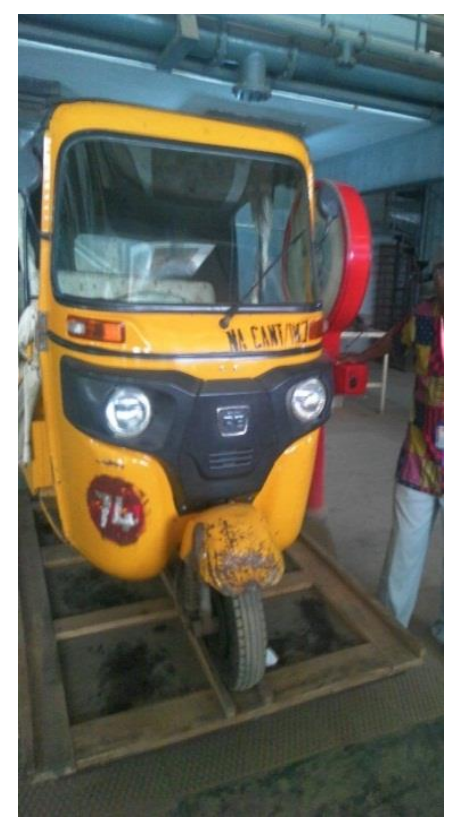

Fig. 2: Weighting of TWST in Fluid Mechanics Laboratory, UNILAG

For the purpose of this work, $72 \mathrm{~kg}$ weight for an adult was adopted based on the random survey that was carried out at Ogun State Property and Investment Cooperation (OPIC) Estate Agbara, Nigeria.

\section{RESULTS AND DISCUSSION}

\subsection{Lateral stability Static Test Results of Model 2006}

Tables 1- 4 show the static test results that were obtained from series of test and calculations that were carried, with the centre of gravity of an average adult taken into consideration [19].

From Table 4, it can be deduced that the vehicle itself without any occupant is laterally unstable. With the driver alone the vehicle becomes stable. The reason is quite obvious. The weight of the driver shifted more load to the front wheel than the rear, bringing down the value of lateral stability below the maximum required. The result is line with that literature [1]. However, with passenger(s) at rear seat, more loads were transferred to the rear wheels than the front wheel because of the position of C. G. of the vehicle. This made the vehicle to be laterally unstable. Therefore, the non-compliance of the vehicle, in terms of lateral stability is due mainly to the loadings at the rear seat. It can be deduced from the variances that the vehicle itself is laterally unstable and it will suffer lateral instability with two occupants and 
above. Therefore, to say that a vehicle is laterally stable when testing it with driver alone, based on ISO 4138 [14], will amount to overlooking the loads which affects lateral stability. There may have been an implicit assumption by ISO that the weight of passengers is not significant when compared with the weight of the vehicle. However, in this case the weights of passengers were significant. From equation (23) it can be seen that the factors that affect lateral stability are the cornering coefficient and load distribution. When the tyres are the same, all other things being equal, the cornering coefficient becomes irrelevant as seen from equations (29) (30) and (31). Therefore, in this case of TWST where the vehicle is laterally unstable, apart from redesigning the vehicle, there are other requirements that can specified to improve the lateral stability of the vehicle based on those two factors. Some of them are:

Tyre type, height and width: Introducing tyres type with higher cornering coefficient, higher height or wider width at the rear, like that of the racing car, will impact positively on the lateral stability of the vehicle. However, manufacturers of non-specialised vehicles like TWST may not be too willing to adopt higher height of tyres because it might increase its centre of gravity. However, they may be willing to adopt the ones with higher cornering coefficient or wider width or both at the rear when compelled to ensure lateral stability of their vehicles. If this happens, dynamic test may be adopted in establishing veracity of their claims.

The tyre pressure does affect lateral stability. Increase in tyre pressure at the rear wheel more than that of the front will impact positively on lateral stability because cornering coefficient increases with tyre pressure. To implement tyre pressure difference on rear and front wheels of TWST in a developing country may be not practicable.

Table 1: Average weight of TWST

AVERAGE $359 \mathrm{~kg}$

Table 2: Average weight of wheel reactions of TWST

\begin{tabular}{llllll}
\hline & $\begin{array}{l}\text { Front Wheel } \\
\text { Reaction in } \mathrm{kg} \\
\mathrm{a}\end{array}$ & $\begin{array}{l}\text { Left Wheel } \\
\text { Reaction in } \mathrm{kg} \\
\mathrm{b}\end{array}$ & $\begin{array}{l}\text { Right Wheel } \\
\text { Reaction in } \mathrm{kg} \\
\mathrm{c}\end{array}$ & $\begin{array}{l}\text { Total Rear } \\
\text { Weight in } \mathrm{kg} \\
\mathrm{b}+\mathrm{c}\end{array}$ & $\begin{array}{l}\text { Total Weight } \\
\text { in } \mathrm{kg} \\
\mathrm{a}+\mathrm{b}+\mathrm{c}\end{array}$ \\
\hline AVERAGE & 108 & 115 & 135 & 250 & 358 \\
\hline
\end{tabular}

Table 3: Weight and horizontal dimension of C.G. of occupants

\begin{tabular}{llll}
\hline $\mathrm{S} / \mathrm{N}$ & Item & Weight in $\mathrm{kg}$ & $\begin{array}{l}\text { Horizontal distance of C.G. from the centre of front } \\
\text { wheel in } \mathrm{m}\end{array}$ \\
\hline 1 & Driver & 72 & 0.9303 \\
2 & Passenger & 72 & 1.6303 \\
3 & TWST & 359 & 1.3928 \\
\hline
\end{tabular}

Table 4: Lateral stability report for TWST

\begin{tabular}{|c|c|c|c|c|c|c|c|}
\hline Item & Occupants & $\begin{array}{l}\text { Total } \\
\text { Weight of } \\
\text { Vehicle } \\
\text { b }\end{array}$ & $\begin{array}{l}\text { Weight on } \\
\text { the Rear } \\
\text { Wheels } \\
\text { c }\end{array}$ & $\begin{array}{l}\text { Actual } \\
c / b \\
d\end{array}$ & $\begin{array}{l}\text { Standard } \\
\mathrm{b} / \mathrm{a}<2 / 3 \\
\text { Maximum } \\
\mathrm{e}\end{array}$ & Variance & $\begin{array}{l}\text { Compliant (C) / } \\
\text { Non-compliant } \\
\text { (NC) } \\
\mathrm{g}\end{array}$ \\
\hline 1 & 0 & 359 & 250 & 0.697 & 0.667 & -0.030 & $\mathrm{NC}$ \\
\hline 2 & 1 = Driver & 431 & 284 & 0.658 & 0.667 & +0.009 & C \\
\hline 3 & $\begin{array}{l}2=\text { Driver }+1 \\
\text { Passenger }\end{array}$ & 503 & 344 & 0.681 & 0.667 & -0.014 & NC \\
\hline 4 & $\begin{array}{l}3=\text { Driver }+2 \\
\text { Passengers }\end{array}$ & 575 & 401 & 0.697 & 0.667 & -0.030 & NC \\
\hline 5 & $\begin{array}{l}4=\text { Driver }+3 \\
\text { Passengers }\end{array}$ & 647 & 460 & 0.711 & 0.667 & -0.044 & $\mathrm{NC}$ \\
\hline
\end{tabular}


The effect of curvilinear motion can impart negatively on lateral stability of TWST. In extreme case of vehicle manoeuvring, the vehicle may essential become a two-wheel vehicle, thereby transferring more load to the outer rear wheel, which will increase lateral instability. Acceleration also transfers more load to the rear wheel thereby increasing lateral instability. These effects can be taken care off in the selection of appropriate tyres for the rear wheels.

The effect of camber. Outward cambering will increase lateral stability. In case of the redesign of the vehicle, the effect cambering of the wheels should be taken into consideration, including suspension, and roll resistance.

There are other factors such as steering compliance, gyroscopic couple due to road bumps, Coriolis force due to curvilinear motion, etc. that could impact negatively on lateral stability. All these will complicate the initial models derived. Therefore, it would be advantageous for now to stick to basic model, which will of course lead to improvement in safety of life and properties of stakeholders in developing countries.

All said and done, as a temporary measure, the current TWST could be fitted with tyres with higher cornering coefficient and wider width like that of racing car at the rear to improve their lateral stability. Another option for lateral instability reduction is ensure that maximum speed of vehicle, when moving in straight line will not attain up that which could cause lateral instability. However, this will limits its commercial purpose of competing with four wheel vehicle. Finally, there should be a major modification of the vehicle at the initial stage of its design to be lateral stability compliant. It could be noted that the current trend in design of tricycle is to have two wheels in front where the stability factors will reinforce each other. However, its limitation is in the number of occupants that can be accommodated, which will defeat the commercial purposes of TWST.

\section{CONCLUSION AND RECOMMENDATION}

\subsection{Conclusion}

This study came up with lateral stability models, which include static test procedure, for the design and regulation of TWV (delta trike) in developing countries, in order to enhance safety of life and properties.

In addition, the test procedure based on the models, were used in the analysis of the lateral stability of one of the commonest TWST on Nigerian road. The vehicle was found to be laterally unstable with two occupants and above. However, this instability could be eliminated on the current TWST by introducing tyres with higher cornering coefficient or wider width at the rear. The ultimate solution lies in redesigning of the vehicle at initial stage to take care of the problem.

\subsection{Recommendation}

The TWST currently being used by developing countries including Nigeria is not too safe in terms of lateral stability due basically to the loadings. Therefore, the following recommendations are made to ensure its lateral stability:

That the Lateral Stability Factor should always be less than $2 / 3$ (with the loadings inclusive) either through design or by the introduction of other safety measures at the rear wheels.

ISO 4138 [14] could be modified to include all the loadings for the purpose of testing vehicles worldwide in order to enhance safety of life and properties.

\section{REFERENCES}

[1]. Gawade, T. R., Mukherjee, S. and Mohan, D. "Six-degree-of-freedom three-Wheeled-vehicle model validation", Journal Automobile Engineering, 219(4): 487-498, 2005.

[2]. Gohl, J., Rajamani, R., Starr, P. and Alexander, L. "Development of a Novel Tilt-Controlled Narrow Commuter Vehicke", University of Minnesota, Minneapolis, 2006.

[3]. Mukherjee, S., Mohan, and Gawade, T. R. "Three-wheeled scotter taxi: A safety analysis", Sadhand Vol. 32,, pp. 459-478, 2007.

[4]. Berote, J. and Van Poelgeest, A., Darling, J., Edge, K. A. and Plummer, A. (, "The Dynamics of a Three-wheeled Narrow-Track Tilting Vehicle", University of Bath, UK, 2008.

[5]. Dardaine, J., Rodier, L. and Venaille, V. "Preliminary Study of a Three-wheel Tandem Powered by a PEN Fuel Cell", FISITA 2008 World Automotive Congress, 2008.

[6]. Huston, J. C., Graves, B. J. and Johnson, D. B. "Three Wheeeeled Vehicle Dynamics", Society of Automotive Engineers, 820139, pp. 45-58, 1982.

[7]. Valkenburgh, P. G. V., Klein, R. H. and Kanianthra, J. "Three-Wheel Passenger Vehicle Stability and Handling", Society of Automotive Engineers, 820140, pp. 59-81, 1982. 
[8]. Karnopp, D. Vehicle Dynamics, Stability and Control, CRC Press Taylor \& Frances Group, Boca Raton, 2013.

[9]. Ellis, J. R. Vehicle Dynamics, Business Books Limited, London, 1969.

[10]. Gillespie, T. D. Fundamentals of vehicle dynamics, SAE, Warrendale, 1992.

[11]. Rajamani, R. Vehicle Dynamics and Control, Springer Science + Business Media, New Yock, 2012.

[12]. Sachdeva, R. C. and Kamiyo, O. Fundamentals of Engineering Heat and Mass Transfer, New Age International Publishers, New Delhi, 2015.
[13]. Goran, S. V., Rakicevic, B. B., Mitic, S. R. and Stamenkovic D. D. "Determination of Connering Stiffness Through Integration of Mathematical Model and Real Vehicle Exploitation Parameters", FME Transactions, Belgrade, 2013.

[14]. ISO 2012, "ISO 4138:2012(E)", ISO, Switzerland, 2012.

[15]. Jazar, N. J. Vehicle Dynamics, Springer Science+Business Media, LLC, New York, 2008.

[16]. Swearingen, J. J. Determination of Centre of Gravity of Man, Federal Aviation Agency, Oklahoma, 1962. 